\title{
AÇõES ESTRATÉGICAS DE IMPLANTAÇÃO DE SISTEMAS AGROFLORESTAIS NO MUNICÍPIO DE PARAGOMINAS - PA
}

\author{
A. O. DOS SANTOS ${ }^{1}$ e R. C. R. DA SILVA ${ }^{2}$ \\ Instituto Federal de Educação, Ciência e Tecnologia do Pará \\ abimaelufra@gmail.com ${ }^{1}$
}

Submetido 21/02/2020 - Aceito 28/04/2020

DOI: $10.15628 /$ holos.2020.9586

\section{RESUMO}

O objetivo deste trabalho foi avaliar ações de implantação de sistemas agroflorestais, por meio da criação de Unidade Demonstrativa de Sistemas Agroflorestais - UDSAF para agricultores familiares na comunidade rural Nazaré, no município de Paragominas -PA. As estratégicas usadas foram as oficinas e a realização de um dia de campo para a divulgação dos resultados. Todo o processo foi construído de forma participativa. A unidade demonstrativa de sistemas agroflorestais (UDASAF) foi formada a partir da união de três áreas: a primeira com 0,5 hectares e cinco anos de implantação, a segunda com 0,15 hectares e um ano de implantação, e a terceira, de 1 hectare, que fez parte deste trabalho. No dia de campo foi aplicada uma pesquisa de avaliação das estratégias de implantação da
UDSAF na comunidade, verificando o interesse dos participantes nos SAF's. O resultado foi que $8 \%$ dos agricultores participantes se mostraram indiferentes $e$ $92 \%$ demonstraram muito interesse. No final do evento as aferições dos questionários mostraram uma eficiência de $100 \%$ para as três perguntas desenvolvidas, a saber, todos os envolvidos disseram que compreenderam o processo de produção em SAF's, que implantariam essa tecnologia em suas propriedades e que recomendariam os sistemas agroflorestais para amigos ou parentes. A estratégia de aliar unidade demonstrativa e realização de dia de campo foi muito exitosa, pois permitiu a possibilidade de transferência de tecnologias e troca de saberes entre os participantes.

PALAVRAS-CHAVE: Comunidades Rurais, Unidades Demonstrativas, Agricultura Familiar.

\section{STRATEGIC ACTIONS FOR THE IMPLEMENTATION OF AGROFORESTRY SYSTEMS IN THE PARAGOMINAS CITY - PA}

\begin{abstract}
The objective of this work was to evaluate actions of implantation of agroforestry systems, through the creation of Demonstrative Unit of Agroforestry Systems UDSAF for family farmers in the rural community Nazaré, in the municipality of Paragominas. The strategies used were the workshops and a field day to disseminate the results. The entire process was built in a participatory manner. The agroforestry systems demonstration unit (UDASAF) was formed from the union of three areas, the first with 0.5 hectares with five years of implantation, the second with 0.15 hectares and one year of implantation, the third with 1 hectare, which was part of this work. On the Field Day, a survey was carried out to evaluate the strategies for implementing UDSAF in the community, checking the interest of participants in the SAF's. The result was that $8 \%$ of participating farmers were
\end{abstract}

indifferent and $92 \%$ showed a lot of interest. At the end of the event, the measurements of the questionnaires showed $100 \%$ efficiency for the three questions developed, namely, everyone involved said that they understood the production process in SAF's, that they would implement this technology on their properties and that they would recommend agroforestry systems for friends or relatives. The strategy of combining a demonstration unit and conducting a field day was very successful, as it allowed the possibility of transferring technologies and exchanging knowledge between the participants.

KEYWORDS: Rural Communities, Demonstrative Units, Family Farming. 


\section{INTRODUÇÃO}

Áreas com plantios agroflorestais apresentam grande potencial para o aumento da biodiversidade e contribuem para diminuir a pressão humana sobre as florestas nativas, devido à sua multifuncionalidade no nível da propriedade e da paisagem (MICCOLINS, et al., 2016). Dessa forma, essas áreas podem se tornar um refúgio para a vida animal, que tolera certo nível de distúrbio de uma dada região, podendo servir também como corredor animal para espécies mais sensíveis.

Assim, os sistemas agroflorestais são considerados sistemas altamente resilientes às mudanças climáticas, pois possuem época de colheita estendida, amenizam os efeitos de eventos extremos como secas prolongadas e enchentes, modificam temperaturas, proporcionam sombra e abrigo e agem como fontes alternativas de alimentos durante os períodos de cheias e secas (LASCO et al., 2014).

No Brasil, os SAF's têm se mostrado como atividade economicamente viável em diferentes contextos, no entanto, essa viabilidade depende da realização de um bom planejamento econômico, o que inclui pesquisa de mercado e execução com técnicas adequadas (SANTOS, 2010). Dessa forma, desponta como alternativa viável para a conciliação entre a obtenção de renda e a preservação ambiental, uma vez que possibilita rendas variadas, decorrentes dos diferentes produtos com baixo impacto ambiental.

Aliado aos modelos sustentáveis, a estratégia de implantação de unidades demonstrativas com experimentação participativa leva os agricultores não apenas ao uso e desenvolvimento de práticas diferenciadas, mas também ao aprendizado acerca das possibilidades de solução dos seus próprios problemas. Isso se dá porque, nesse tipo de experiência, o agricultor também aprende a trabalhar de forma organizada e solidária, desenvolvendo competências que vão além das técnicas produtivas, resgatando antigas formas de trabalho que se realizavam com o enfoque da solidariedade (MDA, 2004)

Nesse sentido, o objetivo deste trabalho foi avaliar as ações e estratégias de implantação de unidade demonstrativa de sistemas agroflorestais - UDSAF para agricultores familiares no município de Paragominas - PA.

\section{METODOLOGIA}

\section{Caracterização da área de estudo}

Este trabalho de avaliação das ações estratégicas de implantação de SAF, por meio da criação da unidade demonstrativa participativa de sistemas agroflorestais - UDSAF, foi realizado na comunidade Nazaré, município de Paragominas, estado do Pará. A comunidade está localizada a $92 \mathrm{Km}$ da sede do município, com acesso pela Rodovia Pa 256, sentido rio Capim (Figura 1). 
De acordo com Santos et al. (1993), essa localidade e as outras existentes no Rio Capim têm em comum, além das condições ambientais, culturais e econômicas, o fato de que suas gerações passadas migraram ao longo do rio no sentido de sua nascente, em busca de maior disponibilidade de floresta primária para a implantação de lavouras (tendo a mandioca como principal produto) e mantendo-se sempre às margens do curso de água.

Essas comunidades vivem dos recursos do rio e de uma agricultura tradicional baseada em sistemas agroflorestais e agricultura de corte e queima (CIRAD, EMBRAPA, UFPA, 2013). Foram escolhidas em função de já estarem participando de Projeto de incentivo a Agricultura de Baixo Carbono, em fase de Implantação pelo Projeto Rural Sustentável do Governo Federal, em parceria com o Governo da Inglaterra e o Banco Interamericano de Desenvolvimento - BID e, ainda, por terem aproximadamente 370 famílias de produtores em seu entorno (ITERPA, 2017).

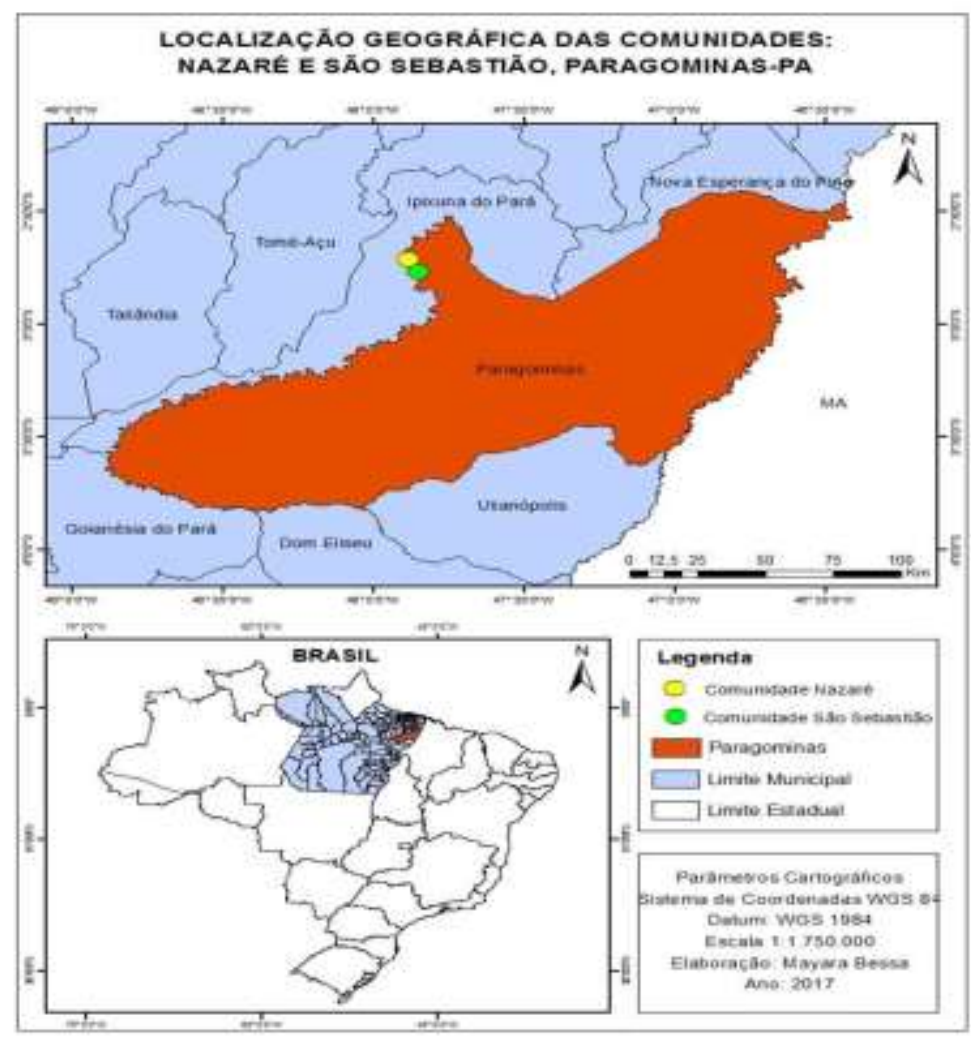

Figura 1: Mapa de localização da área de estudo, município de Paragominas-Pa.

\subsection{Ações estratégicas de implantação de SAF}

\subsubsection{Processo de sensibilização da comunidade}

Para o início do planejamento do referido projeto, foram realizadas reuniões em outubro de 2017 e março de 2018, contando com a participação em primeiro lugar de produtores que já estavam engajados em outro projeto (Pará Rural), desenvolvido pelo Instituto de Desenvolvimento Florestal e da Biodiversidade do Estado do Pará - Ideflor Bio, com finalidades semelhantes. Contou-se, ainda, com a participação de representantes dessas entidades, para verificar se havia interesse em participar do projeto. Como resposta, tivemos 
a aceitação por parte tanto dos vinte produtores participantes do programa como por parte da Instituição.

O primeiro passo para o início das atividades foi o estabelecimento de um processo de comunicação entre as partes envolvidas, atribuindo as responsabilidades para execução do projeto. Esse processo se deu através de encontros que definiram o perfil da comunidade envolvida, sua história, suas pretensões para implantação dos SAF's e o estabelecimento de um acordo de cooperação, tendo em vista que a mesma apoiava a implantação do Projeto e se responsabilizava pela condução.

Em seguida, foi feita a escolha do local, um ponto estratégico para ser implantada a Unidade Demonstrativa, em uma propriedade que já tinha um SAF e seu proprietário aceitou a ampliação da área.

Para a formação dos agricultores, foi ministrada uma oficina de implantação de sistemas agroflorestais no mês de fevereiro de 2019, de forma que foram discutidas questões técnicas, de planejamento e um momento de reflexão-ação crítico, que fosse capaz de gerar conscientização das potencialidades produtivas, culturais, econômicas, sociais e ambientais dos SAF's.

\subsubsection{Implantação da Unidade Demonstrativa do Sistema Agroflorestal (UDSAF)}

Para implantação da UDSAF, usou-se como estratégia o processo de construção coletiva com a participação dos agricultores, para empoderamento dessa atividade.

\subsubsection{Definição do arranjo}

A escolha do arranjo produtivo se deu de forma participativa, considerando fatores como: aptidão edafoclimática das espécies a serem implantadas; facilidade de manejo; calendário agrícola, respeitando a temporariedade de produção de cada componente vegetal; um vislumbre do mercado (através das expertises dos agentes públicos de desenvolvimento); caracterização das potencialidades agrícolas/ecológicas da região; e um breve estudo de capital.

A UDSAF foi constituída por três áreas (Figura 2), sendo uma medindo $100 \mathrm{~m} \times 50 \mathrm{~m}(0,5$ hectares), com cinco anos de implantação contendo as espécies: abacaxi (Ananas comosus (L.) Merril); açaí (Euterpe oleracea Mart.); banana (Musa paradisíaca L.); ingá (Inga edulis Mart.); ipê (Handroanthus albus (Chamiso) Mattos); mandioca (Manihot esculenta Crantz); milho (Zea mays L.); jatobá (Hymenaea courbaril L.); e paricá (Schizolobium amazonicum Huber ex Ducke).

A segunda, com medidas de $30 \mathrm{~m}$ por $50 \mathrm{~m}$ (0,15 hectares), com um ano de implantação e as seguintes espécies: abacaxi (Ananas comosus (L.) Merril); açaí (Euterpe oleracea Mart.); banana (Musa paradisíaca L.); ingá (Inga edulis Mart.); ipê (Handroanthus albus (Chamiso) Mattos); mandioca (Manihot esculenta Crantz); milho (Zea mays L.); jatobá (Hymenaea courbaril L.); piquiá (Caryocar brasiliense Cambess.); e uxi (Endopleura uchi (Huber) Cuatrec.). 
A terceira, com medidas variadas, perfazendo um total de 1 hectare, implantada em 2019 e contendo as espécies: abacaxi (Ananas comosus (L.) Merril); açaí (Euterpe oleracea Mart.); banana (Musa paradisíaca L.); ingá (Inga edulis Mart.); ipê (Handroanthus albus (Chamiso) Mattos); mandioca (Manihot esculenta Crantz); milho (Zea mays L.); cacau (Theobroma cacao L.); cupuaçu (Theobroma grandiflorum (Willd. ex Spreng.) K. Schum.) e; urucum (Bixa orellana L.). Ressaltando-se que a área implantada por este projeto se refere à última mencionada, uma vez que as demais já estavam implantadas e serviram de referência na apresentação da tecnologia.

\subsubsection{Análise e correção de solo}

A amostragem do solo para implantação da UDSAF foi realizada seguindo as recomendações da Embrapa, contidas no Manual de Descrição e Coleta de Solo no Campo (EMBRAPA, 2005). As amostras de material de solo foram analisadas no Laboratório Terra Análises Agropecuária LTDA, situado na cidade de Goiânia, conforme metodologia descrita no Manuel de Análise de Solo da Embrapa (EMBRAPA, 2017).

A correção do solo foi feita a partir dos resultados da análise do solo (Tabela 1), com a aplicação de calcário dolimítico. Essa atividade foi realizada com 30 dias de antecedência do plantio, em função da baixa solubilidade do cálcio e magnésio no solo (PREZOTTI; GUARÇONI, 2013).

Tabela 1: Resultado da análise de solo da área do SAF.

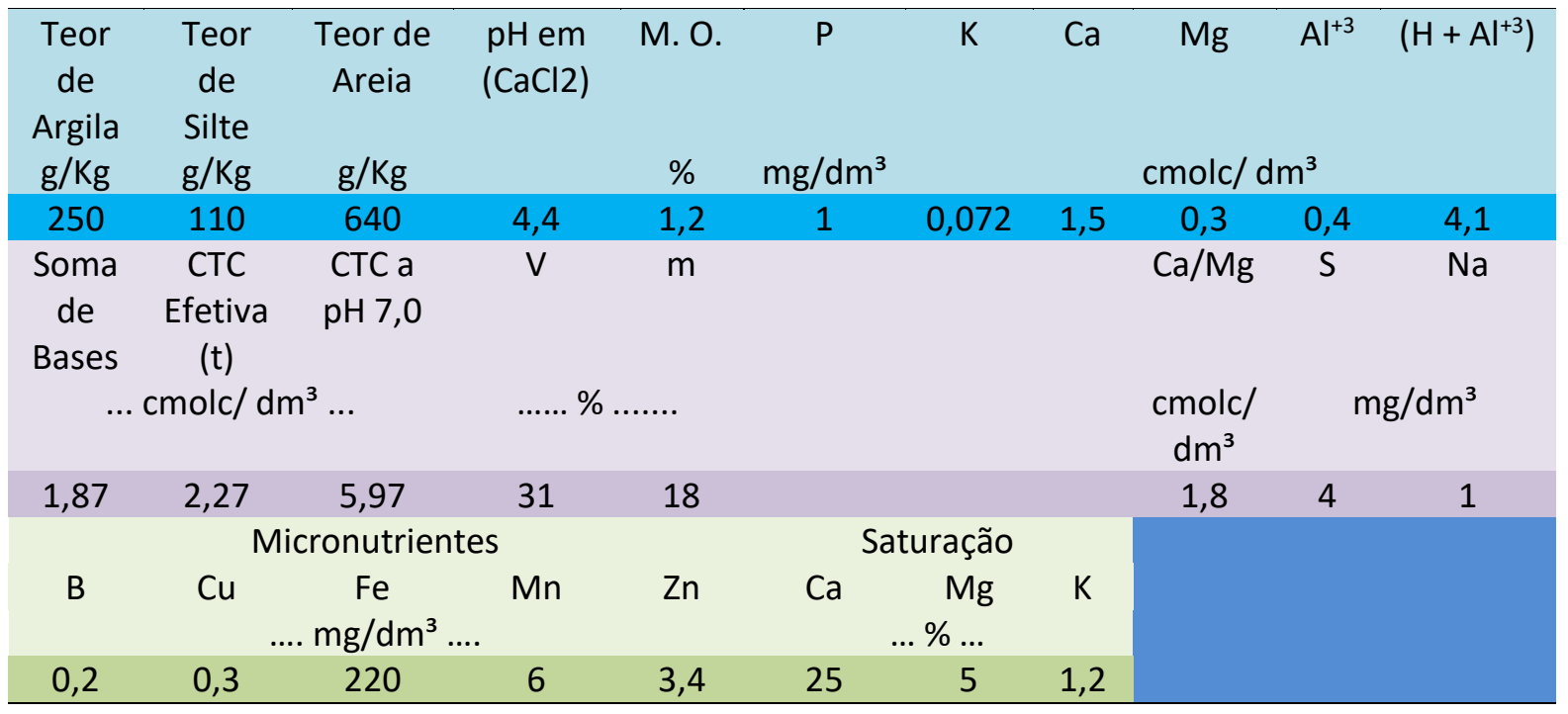

\subsubsection{Preparo de área, plantio e adubação}

Essa etapa seguiu as recomendações técnicas de acordo com a escolha do arranjo implantado no local e o plano de ação que foram definidos em reuniões com a comunidade e a Secretaria de Agricultura de Paragominas - SEMAGRI. 
As práticas de preparo da área realizadas foram: limpeza da área com a remoção da vegetação, seguida de abertura de covas, adubação orgânica, e administração de duas pás de esterco de gado por cova. Após essa etapa, foi realizado o plantio das espécies componentes dos sistemas agroflorestais em covas de $40 \times 40 \times 40 \mathrm{~cm}$.

Em relação à adubação, foi realizada tanto a orgânica, na qual foi administrada uma quantidade de duas pás de esterco de gado por cova, quanto a adubação química, na qual foram calculados os valores de nitrogênio $(N)$, fósforo $(P)$ e potássio $(K)$ recomendados para a produção de cada espécie, de acordo com a análise do solo, sendo selecionadas as espécies mais cultivadas entre arbóreas e frutíferas, presentes no SAF implantado. Nos fertilizantes químicos, o nitrogênio, o fósforo e o potássio estão expressos na forma de N, P2O5 e K2O, (constituídos, respectivamente, dos adubos de cloreto de potássio $\mathrm{KCl}$, mono-amônio-fosfato - MAP e sulfato de amônia - (NH4)2SO4).

As doses de NPK foram parceladas em três momentos: 0, 30 e 60 dias após o plantio. Segundo Borges et al. (2002), o parcelamento das adubações vai depender da textura e da capacidade de troca catiônica do solo, bem como do regime de chuvas e do manejo adotado. Em solos arenosos e com baixa CTC (como é o caso aqui), deve-se parcelar a adubação para evitar perdas por lixiviação. As recomendações de NPK estão baseadas em Malavolta (1981) e Natale \& Rozane (2018).

\subsection{Socialização e avaliação da UDPSAF}

Após a implantação da UDSAF, foi realizado o dia de campo para os agricultores familiares da Comunidade Nazaré e seus arredores, com o intuito de apresentar a tecnologia de implantação dos sistemas agroflorestais.

Também foi realizada uma avaliação junto aos agricultores que participaram do projeto para verificar o nível de aceitabilidade dessa tecnologia. Essa análise foi dividida em duas etapas. A primeira foi formada com um questionário com duas perguntas: Você sabe o que é um sistema agroflorestal? Qual o seu interesse em sistemas agroflorestais; o segundo questionamento constou de três perguntas: Você entendeu o processo de produção dos sistemas agroflorestais? Você implantaria um sistema agroflorestal? Você recomendaria o sistema agroflorestal para um amigo?

\section{RESULTADOS E DISCUSSÃO}

3.1 Avaliação da implantação de UDSAF na comunidade Nazaré no município de Paragominas-Pa

A criação da Unidade Demonstrativa (Figura 2) na comunidade estabeleceu diálogos, exemplificou e potencializou programas de trabalhos associados à inovação ou à conservação ambiental, como é o caso do Programa Municípios Verdes, do governo do Estado, e o Rural Sustentável, do Governo Federal em parceria com o Governo da Inglaterra. Nesse sentido, há 
a possibilidade de irradiar efeitos inovadores dentro da Comunidade, tanto da perspectiva do agricultor monitor como da perspectiva dos agricultores não praticantes de SAF's, mas que residem na mesma comunidade.

Essa estratégia permite que o agricultor use a nova tecnologia numa escala menor, podendo mostrá-la para a comunidade de agricultores locais por meio do "dia de campo", comprovando sua utilidade ou não na propriedade. Outra função das Unidades Demonstrativas é a função didática, pois elas podem e devem ser implementadas em parcerias com escolas agrotécnicas, universidades e entidades de extensão rural, como forma de complementar as atividades práticas dos alunos (EMBRAPA, 2010).

No âmbito do PDRS (Projetos de Desenvolvimento Rural Sustentável), promovido pela SMA/SP (Secretaria de Meio Ambiente do Estado de São Paulo), alguns projetos conduziram os processos de implantação de sistemas agroflorestais e formação dos agricultores através de mutirões. No Assentamento Sepé Tiaraju, em Serra Azul/SP, em projeto do PDRS acompanhado pela ONG Mutirão Agroflorestal, o processo de implantação das áreas se deu através de mutirões, formados por grupos de agricultores, técnicos e estudantes em sinergia. Um processo muito rico que envolve a eficiência dos plantios, as trocas, a construção do conhecimento, o empoderamento e a união. Alguns grupos dentro do Assentamento mantiveram a prática dos mutirões constantemente, mantendo-se fortalecidos e unidos pela Agrofloresta (AMADOR, 2018).

A escolha da área do agricultor familiar, proprietário do Sítio da Paz, foi motivada pela iniciativa de ser o pioneiro em implantar um sistema agroflorestal em sua propriedade naquela comunidade e também pelo grau de conhecimento que ele e sua esposa mostram em relação às questões práticas e técnicas relacionadas ao tema.

Chama bastante atenção a forma como o produtor se relaciona com a terra e consequentemente com as atividades nela desenvolvidas. Há uma preocupação não apenas em obter rendimentos, mas também com a preservação dos recursos naturais e isso faz com que o mesmo seja uma referência naquela região, justamente por ir na contramão da tendência da monocultura e do extrativismo predatório.

A iniciativa de implantar um sistema agroflorestal há seis anos se deu, como já mencionado, por influência do IDEFLOR/BIO, porém, de forma bastante complicada, uma vez que os recursos e as etapas do projeto não foram concluídas na íntegra, o que não desanimou o referido produtor, que, por conta própria, resolveu fazer uma experiência inicial e implantou meio hectare, com muita dificuldade, mas seguindo as recomendações que havia aprendido nas capacitações promovidas pelo Instituto de Florestas do Pará.

A escolha das espécies trabalhadas no SAF está em função da capacidade de trabalho do produtor, da possibilidade de agregação de valor, com espécies madeireiras nobres, facilidade de manejo e benefícios ambientais e de solo que a interação entre as mesmas proporcionam, lembrando que nada foi imposto e sim discutido de forma participativa pela comunidade e, principalmente, pela família do produtor. 
De acordo com Nobre, et al. (2017), a transformação do sistema tradicional do roçado de corte e queima ou plantio e arranque na Amazônia, para os sistemas agrícolas alternativos, como os SAFs, depende fundamentalmente de dois fatores: o processo de sensibilização por parte dos atores sociais (agricultores, técnicos, pesquisadores e estudantes) e a preocupação com o arranjo e o manejo do agroecossistema no período de implantação e consolidação dos SAFs.

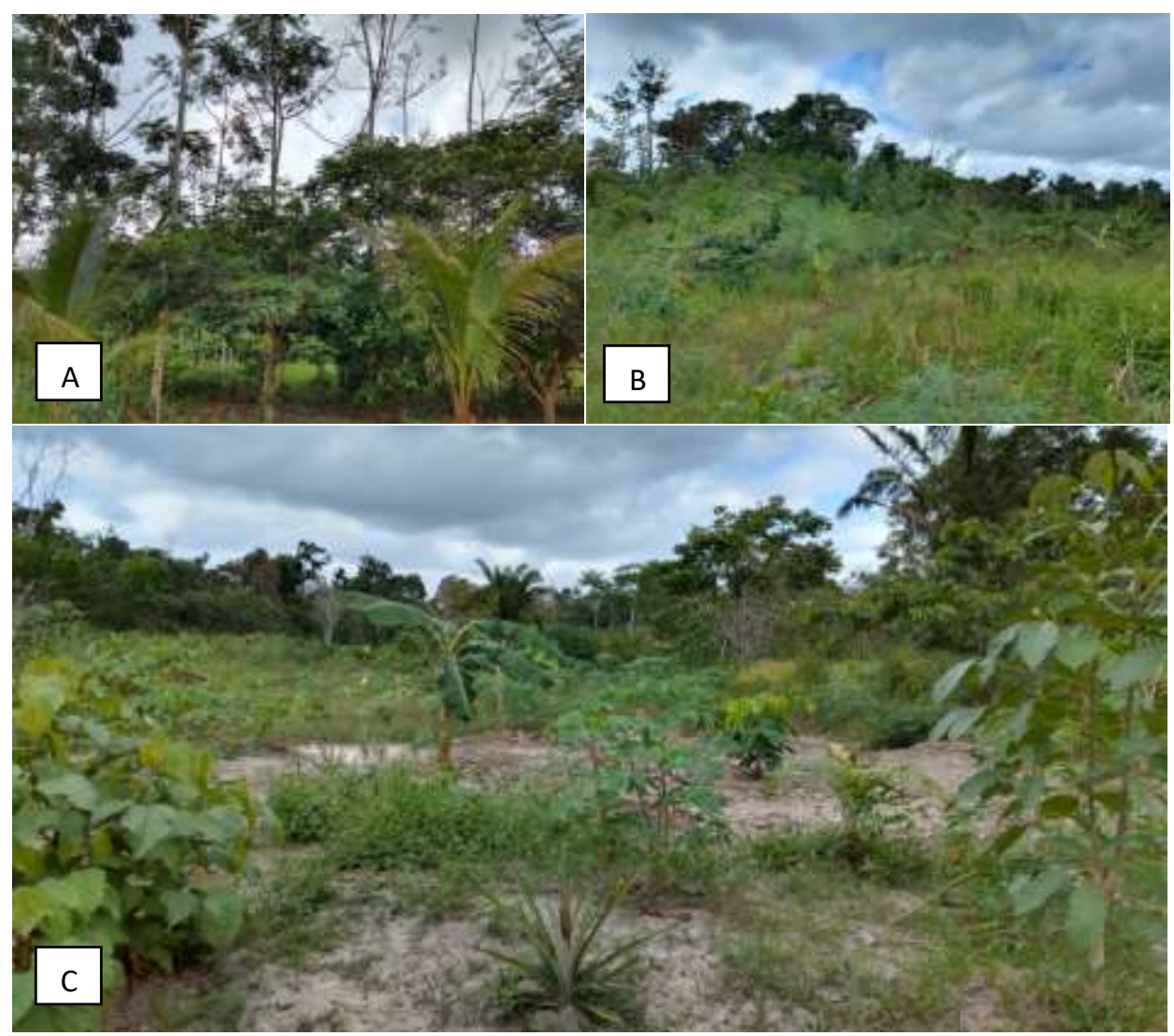

Figura 2: Visão geral da UDPSAF - A: Área 1 (cinco anos); B: Área 2 (dois anos) e; C: Área 3 (nova) na comunidade Nazaré no município de Paragominas-Pa.

\subsection{Socialização da UDSAF}

Toda a comunidade foi mobilizada para o evento, assim como alunos e produtores rurais de outras localidades, sendo elaborado um convite, distribuído para o público alvo e amplamente divulgado em rádio e TV locais, com antecedência de um mês do evento. Também foi colocada uma faixa na entrada da propriedade com as informações do evento e elaborados cartazes para serem afixados nas instituições parceiras, como estratégia de divulgação do evento.

$\mathrm{Na}$ área foram montadas três estações, sendo uma no sistema agroflorestal implantado em parceria com a secretaria de agricultura, objeto deste estudo, outra no sistema agroflorestal com um ano de idade e a última no SAF com cinco anos. Em cada estação os participantes permaneceram por cerca de quarenta minutos, onde foi informado dos arranjos 
e interação concomitante com os participantes (Figura 3). O evento teve início às 8h30min e término às $11 \mathrm{~h}$.

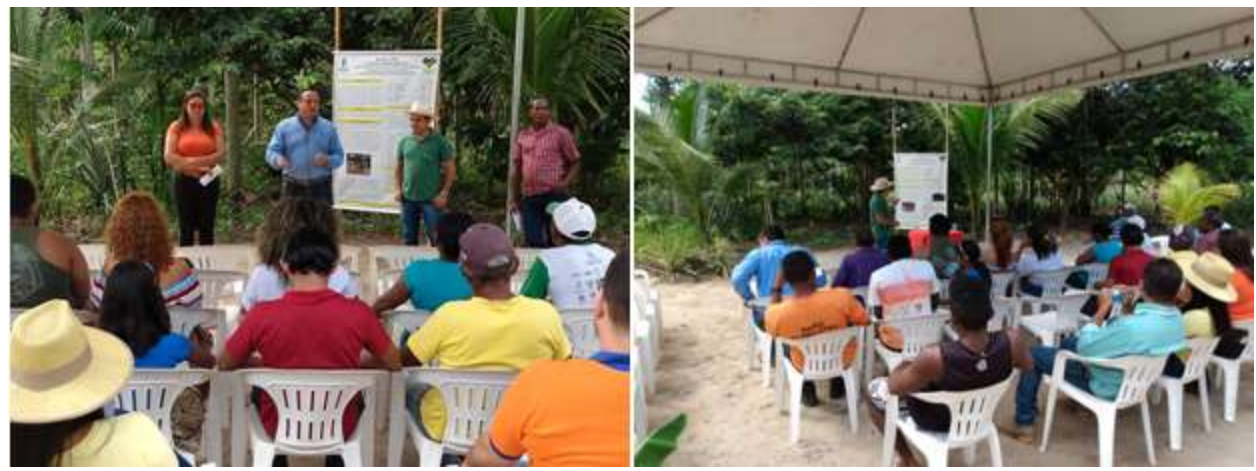

Figura 3: Participação no Dia de campo de sistemas agroflorestais na comunidade Nazaré, no município de Paragominas-Pa.

\subsection{Avaliação da sensibilização da UDSAF}

Quanto à avaliação da sensibilização da metodologia de implantação dos SAF's após análise dos questionários aplicados no início do evento, no universo de 40 participantes, $64 \%$ responderam que já sabiam o que era um sistema agroflorestal e os outros $36 \%$ desconheciam a tecnologia (Figura 4A). Isso demonstra que a maioria dos presentes já tinha algum conhecimento sobre SAF's, o que pode ser justificado pelas diversas ações de implantação de sistemas agroflorestais na comunidade por órgãos de diferentes esferas governamentais.

Com relação ao interesse dos participantes nos SAF's o resultado foi: $8 \%$ foram indiferentes e $92 \%$ demonstraram muito interesse, sendo que ninguém respondeu que não tem interesse, nem pouco interesse, bem como não houve resultado para interesse razoável (Figura 4 B). Esse resultado também pode ser explicado pela ação anterior dos órgãos governamentais. Percebe-se que há bastante interesse e aceitação dessa tecnologia, o que é de extrema importância para a propagação de ações de multiplicação dos sistemas agroflorestais, não apenas naquela comunidade, mas em todo o município.

Resultados similares foram obtidos por Nobre, et.al. (2012), analisando o interesse de assentados na implantação de SAF: das 32 famílias entrevistadas, a maior parte $(84,3 \%)$ participou das atividades desenvolvidas pelo projeto de SAFs da EMBRAPA. Segundo depoimentos, essa participação proporcionou às mesmas um importante aprendizado e uma rica troca de experiência entre os participantes. Além de doze famílias que participaram desse projeto e que ainda não têm SAFs, a grande maioria $(83,3 \%)$ mostrou-se interessada em implantar o sistema.

Oliveira (2011), estudando a perspectiva de uso de SAF em Piraí-RJ, chegou aos resultados obtidos em relação ao conhecimento dos produtores sobre os SAFs: $5 \%$ (2) conheciam os conceitos de SAF, 39\% (12) disseram já ter ouvido falar no assunto e $56 \%$ (16) relataram desconhecer o significado do termo. Contudo, após explicações técnicas sobre o sistema, parte dos produtores relatou entender que é uma forma natural de manejo da 
produção, encontrada em locais onde se tem maior número de espécies arbóreas. A partir disso a maior parte dos proprietários mostrou-se interessada em obter mais conhecimento sobre essa forma de uso da terra, pois as árvores podem melhorar a questão econômica das famílias rurais.

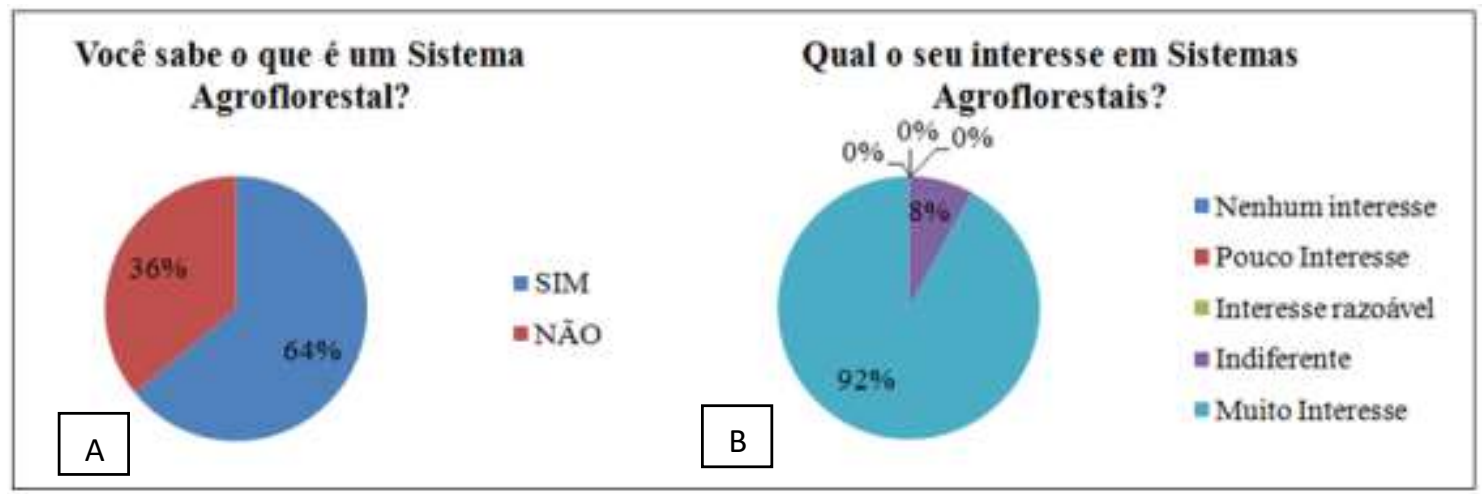

Gráfico 4: Pré-avaliação do dia de campo: A - Conhecimento sobre SAF's e, B - Interesse em Sistemas Agroflorestais na comunidade Nazaré, no município de Paragominas-Pa.

No final do evento, as aferições dos questionários mostraram uma eficiência de 100\% para as três perguntas desenvolvidas, a saber, todos os envolvidos disseram que compreenderam o processo de produção em SAF's, que implantariam essa tecnologia em suas propriedades e que recomendariam os sistemas agroflorestais para amigos ou parentes. (Figura 5: A, B, C).

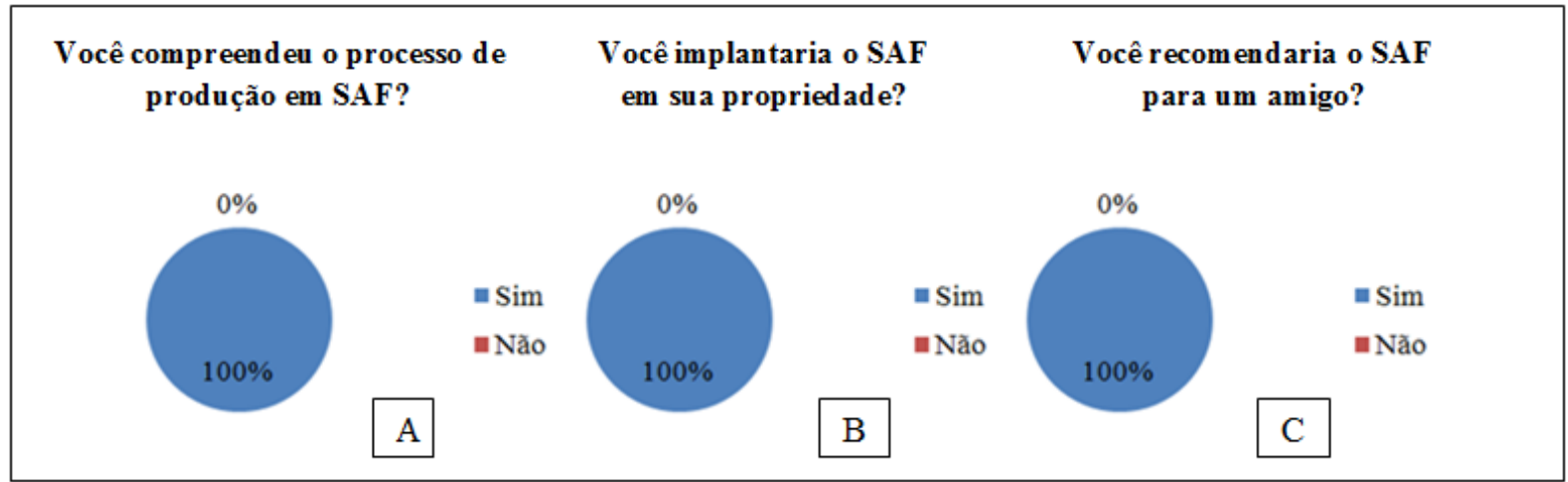

Figura 5: Avaliação do dia de campo: A - Compreensão sobre o processo de produção em SAF; B Implantação do SAF na propriedade e; C - Recomendação do SAF.

Para a comunidade local que participou do processo de difusão das técnicas sustentáveis apresentadas durante o dia de campo, foi possível demonstrar a qualidade e a viabilidade dos sistemas agroflorestais. $\mathrm{O}$ fato de observarem o modelo de produção nessa unidade dá certeza de que esses funcionam e são ferramentas economicamente viáveis, tirando esse saber da esfera abstrata e colocando-o de forma prática e lúdica à disposição dos agricultores daquela região. $O$ impacto da ação pode ser constatado a partir dos relatos feitos pelos participantes durante o dia de campo, visto que foi observada a procura pelos técnicos 
para sanar dúvidas e planejar visitas em suas propriedades para receberem orientação de como implantar as técnicas em suas propriedades.

Mazer et al (2013), em trabalho intitulado "Dia de campo e difusão de tecnologias para a agricultura familiar", concluiu que, após o evento, agricultores dos demais assentamentos da região optaram por implantar as tecnologias apresentadas em seus sistemas de produção, demandando serviços de assistência técnica e extensão rural à equipe do projeto, mostrando assim que, em geral, essa metodologia, quando bem trabalhada, gera interesse no público alvo.

Os SAFs conduzidos sob essa perspectiva vão além de qualquer modelo préestabelecido de agricultura e propõem sustentabilidade a partir de conceitos básicos, que aproveitem o conhecimento local daqueles que vivem no ecossistema e desenhem sistemas que se adaptem ao potencial natural do lugar (GOSTCH, 1995).

\section{CONCLUSÃO}

Como benefício na adoção de SAFs, pode-se citar a variabilidade de espécies utilizadas nos modelos de plantio, a melhoria da capacidade produtiva da terra e a otimização da utilização dos recursos naturais disponíveis, se adaptados às condições ecológicas e dos produtores, obtendo assim uma maior produção por unidade de área. A diversificação de culturas ocasiona uma melhora significativa das propriedades físicas, químicas e biológicas do solo, por meio de ciclagem de nutrientes e controle de erosão. Dessa forma, fica evidente que essa proposta de desenho produtivo é, sem dúvida alguma, promissora para o município e a região, podendo contribuir de forma significativa para o desenvolvimento local de forma sustentável.

Acredita-se que a estratégia de aliar a unidade demonstrativa com a realização do dia de campo foi muito exitosa, pois permitiu a possibilidade de transferência de tecnologias e troca de saberes entre os participantes, além de possibilitar aos estudantes presentes no evento compreender as técnicas de extensão que são aceitas pela comunidade local. Para os agricultores, a unidade demonstrativa serviu para visualizar o resultado das técnicas trabalhadas, assim como permitir que os mesmos explorem as diversas possibilidades de utilização e de novos arranjos a serem adotados em suas propriedades. Isso permite dizer que a estratégia de implantação de Unidade Demonstrativa é, sem sombra de dúvidas, uma ferramenta de extremo potencial para o avanço e adoção de tecnologias mais apropriadas para a agricultura familiar.

No decorrer desta pesquisa, foi demonstrado o potencial dos sistemas agroflorestais para os agricultores familiares do município de Paragominas-Pa, como forma de diversificação das propriedades, segurança alimentar e produtora de serviços ambientais, de maneira a contrapor a hegemonia dos monocultivos de grãos na região. 


\section{REFERÊNCIAS}

AMADOR, D. B. et al. Educação agroflorestal e a perspectiva pedagógica dos mutirões agroflorestais. Cadernos de Agroecologia, v. 13, n. 1, 2018.

BORGES, A. L.; RAIJ, B. van; MAGALÃES, A. F. de J.; BERNARDI, A. C. de C.; LIMA, A. de A. Nutrição mineral, calagem e adubação do maracujazeiro irrigado. Cruz das Almas: Embrapa Mandioca e Fruticultura, 2002, 8 p. (Embrapa Mandioca e Fruticultura. Circular Técnica, 50).

CIRAD, EMBRAPA, UFPA. Realidades e perspectivas da agricultura familiar no município de Paragominas - Pa. Relatório de Pesquisa, 38 p. Paragominas. 2013.

EMBRAPA. Manual de descrição e coleta de solo no campo, por R. D. dos Santos e outros autores. 53 ed. revista e ampliada Viçosa, Sociedade Brasileira de Ciência de Solo, 2005.

EMBRAPA. Manual de métodos de análise de solo / Paulo César Teixeira ... [et al.], editores técnicos. - 3. ed. rev. e ampl. - Brasília, DF: Embrapa, 2017. 574 p.

EMBRAPA 2010. OLIVEIRA; M, G, de C. \& OLIVEIRA; F. S. C. de. A utilização de Unidades Demonstrativas para a transferência de tecnologia. Disponível em: http://www.clicnews.com.br/agropecuaria/view.htm?id=117997. Acessado em 10 de janeiro de 2018.

GÖTSCH, E. Break-through in agriculture. Rio de Janeiro: AS-PTA, 1995.

ITERPA. Relatório de Gestão 2017. Belém. 2018. Disponível em: http://www.iterpa.pa.gov.br/sites/default/files/relatorio de gestao 2017.pdf. Acessado em 20 de Fevereiro de 2019.

LASCO, R. D.; DELFINO, R. J. P.; ESPALDON, M. L. O. Agroforestry systems: helping smallholders adapt to climate risks while mitigating climate change. Wiley Interdisciplinary Reviews: Climate Change, v. 5, p. 825-833, 2014.

MALAVOLTA, E. Manual de química agrícola adubos e adubação. São Paulo: Ed. Agronômica Ceres, 1981, 3 ed. 595 p.

MAZER, G. P. et al. Dia de campo e difusão de tecnologias para a agricultura familiar. Revista Conexão UEPG, v. 9, n. 1, p. 106-119, 2013.

MDA, Manual para elaboração de projetos de unidade demonstrativa. Recife, julho de 2004. P.5.

MICCOLIS A. et al. Restauração Ecológica com Sistemas Agroflorestais: como conciliar conservação com produção. Opções para o cerrado e caatinga. Brasília: Instituto Sociedade, População e Natureza - ISNP/ Centro Internacional de Pesquisa Agroflorestal - ICRAF, 2016. 266p. 
NATALE, W.; ROZANE, D. E. Análise de solo, folhas e adubação de frutíferas. Registro: Ed. UNESP, 2018, $124 \mathrm{p}$.

NOBRE, H. G.; SILVA, F. S. N.; OLIVEIRA, D. S.; BENEVIDES, P. R.; ARAÚJO, E. R. Agroecologia, sistemas agroflorestais e sua contribuição para a sustentabilidade no Nordeste Paraense. In: Canuto, J. C. Sistemas Agroflorestais: experiências e reflexões / João Carlos Canuto, editor técnico. Brasília, DF: Embrapa, 2017. 216 p.

NOBRE, H. G.; JUNQUEIRA, A. da C.; SOUZA, T. J. M.; RAMOS FILHO, L. O.; CANUTO, J. C. Utilização de práticas agroecológicas na construção de projetos sustentáveis para a reforma agrária: um estudo de caso no assentamento Sepé Tiaraju-SP. Revista Brasileira de Agroecologia, Cruz Alta, v. 7, n. 1, p. 3-13, 2012.

OLIVEIRA, T. L. da C. Sistemas agroflorestais: perspectivas de uso em propriedades rurais na Região de Cacaria, Piraí-RJ. Seropédica-RJ Novembro-2011. Monografia URRJ.

PREZOTTI, L. C.; GUARÇONI M. A. Guia de interpretação de análise de solo e foliar. Vitória, ES: INCAPER, 2013. $104 \mathrm{p}$.

SANTOS, A. C. dos. O papel dos sistemas agroflorestais para usos sustentáveis da terra e políticas relacionadas - Indicadores de Funcionalidade Econômica e Ecológica de SAFs em Redes Sociais da Amazônia e Mata Atlântica, Brasil. PDA/Ministério do Meio Ambiente MMA, Brasília, DF. 2010.

SANTOS, M. L. M. Utilização de imagens de satélite no mapeamento preliminar do uso da terra e na capacitação de agricultores do médio rio Capim - Paragominas - Pa Brasil. Anais do VII Simpósio Brasileiro de Sensoriamento Remoto (SBSR). Curitiba - PR. 1993. Disponível em: $\quad$ http://marte.sid.inpe.br/col/dpi.inpe.br/marte@80/2008/06.16.18.37/doc/006015.pdf. Acessado em 06 de Junho de 2019. 